\title{
Erratum to: Chapter 5, 6, 7 and 8 of PET/CT in Gynecological Cancers
}

\author{
Tara Barwick and Andrea Rockall
}

(C) Springer International Publishing Switzerland 2016

T. Barwick, A. Rockall (eds.), PET/CT in Gynecological Cancers,

Clinicians' Guides to Radionuclide Hybrid Imaging,

DOI 10.1007/978-3-319-29249-6

The below mentioned copyright comment has been included in Chapters 5, 6, 7 and 8:

\section{Comment:}

The content of this chapter has originally been published in: Szyszko: PET/CT in Esophageal and Gastric Cancer, (C) Springer 2016.

The updated original online version of the chapter can be found at

DOI 10.1007/978-3-319-29249-6_5

DOI 10.1007/978-3-319-29249-6_6

DOI 10.1007/978-3-319-29249-6_7

DOI 10.1007/978-3-319-29249-6_8 